\title{
Dehydrational crises: a major risk factor in blinding cataract
}

\author{
D C MINASSIAN,' V MEHRA, ${ }^{2}$ AND J-D VERREY' \\ From the 'International Centre for Eye Health, Institute of Ophthalmology, 27-29 Cayton Street, London \\ EC1V 9EJ, and the ${ }^{2}$ Chattisgarh Eye Hospital, Fafadih, Raipur, MP, India
}

SUMMARY An earlier case control investigation has indicated a strong relationship between dehydrational crises and risk of presenile cataract. A second methodologically distinct case control study of risk factors in cataract has been carried out in a population very different in terms of environmental and sociocultural characteristics from the population investigated in the earlier study in Central India. The results strongly confirm the findings from the first study and indicate that an estimated $38 \%$ of blinding cataract may be attributable to repeated dehydrational crises resulting from severe life threatening diarrhoeal disease and/or heatstroke. The risk of blinding cataract was strongly related to level of exposure to dehydrational crises in a consistent and dose dependent manner, thus indicating a causal association. The findings are discussed in relation to possible sources of bias in the study, confounding in the data, and the steps that were taken to minimise their undesirable effects.

\begin{abstract}
A matched-pair case-control study conducted in Raipur, Central India, has shown for the first time that the risk of presenile cataract may be substantially increased by exposure to severe life threatening diarrhoeal disease and to heatstroke.' The data suggest that approximately $40 \%$ of the cataracts in the population studied might be attributed to crises of severe dehydration. If these findings could be substantiated and generalised to other populations in India and elsewhere, then a major cause of the biggest blinding disease worldwide would have been discovered. To this end a methodologically distinct case control study was conducted in Titlagarh, Orissa, in a population that was markedly different from that in Raipur in terms of ethnic, socioeconomic, cultural, and environmental factors.
\end{abstract}

\section{Material and methods}

The study was carried out in a small eye unit in a long established general practice in the town of Titlagarh in Orissa. The eye unit serves a good mixture of urban and rural populations from the town and its surrounding villages, providing a high-quality primary eye care service and referral for intraocular surgery, free of charge.

Correspondence to D C Minassian.
During a 24-month period all patients aged 30 to 69 who attended the eye unit and who could be categorised as cases (cataract) or controls, according to a predefined set of diagnostic criteria, were included in the study. There was no deliberate selection of controls by matching.

All the systematic examinations and interviews were conducted by one specially trained ophthalmic assistant working under the supervision of the senior physician in charge of the practice, with regular and frequent quality control checks made by one or other of the ophthalmologists in charge of the study. Throughout the period of field work the ophthalmic assistant was unaware of the definition of cases and controls.

\section{EXAMINATIONS}

All patients aged 30 to 69 attending the eye unit during the study period were systematically tested and examined to assess visual acuity and central lens opacities. The red reflex of each eye was visualised through the undilated pupil with a direct ophthalmoscope set at $+2 \cdot 00$ dioptres and held at approximately $1 / 3 \mathrm{~m}$ from the patient's eye. Central lens opacities that partially (or wholly) obscured the red reflex were identified and graded as $0,1,2 \mathrm{a}, 2 \mathrm{~b}$, or 3 according to the area of opacity in relation to area of clear red reflex. Grade 3 indicated complete obscuration of the 
red reflex by the lens opacity. In addition aphakia was recorded as grade 4, and grade 5 indicated inadequate view or unable to assess the red reflex, usually due to corneal opacity. The standard method of examination and grading of central lens opacities has been assessed in the field in an observer variation study and is described in more detail elsewhere. ${ }^{2}$ Further detailed eye examinations including refraction and funduscopy were carried out according to the diagnostic routine of the clinic.

The general examinations included measurement of the patient's height and weight as an index of nutritional status and screening for diabetes.

DEFINING THE CASES AND THE CONTROLS

The predefined criteria for diagnosis of the 'case' (unknown to the examiner and interviewer) were 'sufficiently advanced central lens opacity (grade $2 \mathrm{~A}$ or worse) $)^{2}$ that impaired the vision to less than $6 / 18$ '. All the remaining patients were taken as unselected controls.
INTERVIEW

The interviews took place in a specially prepared area in the clinic, away from the busy routine of the practice. The interview procedure, used in the study to ascertain exposure to the possible risk factors under investigation, had been previously tested and standardised in extensive pilot studies covering more than 600 interviews in rural and urban settings. In particular, the key questions, which concerned past experience of severe life threatening diarrhoeal disease, were tested and refined (with due regard to the local culture) so that they focused on episodes of illness that should have been memorable. Fig. 1 shows the sequence and the English translation of the questions that were asked systematically and in a standard fashion in all the study subjects regardless of their cataract status.

To avoid possible recall bias the diarrhoea questions were hidden among many other interview topics which included smoking habits, tobacco chewing, access to clean water, occupation, etc. Past

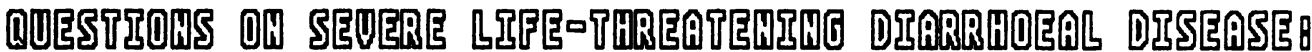

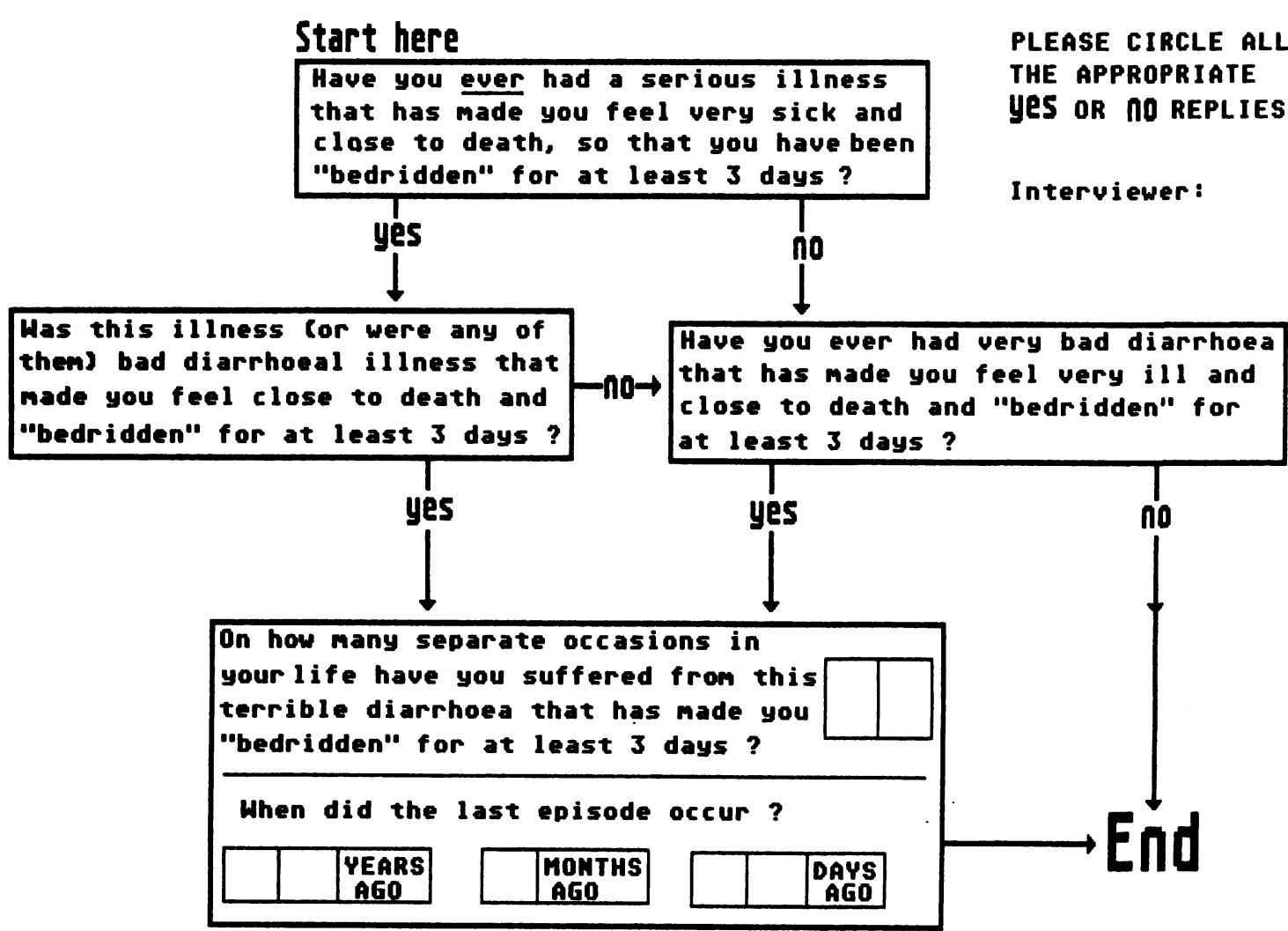

Fig. 1 Content and flow of questions to ascertain past exposure to severe cholera-like diarrhoeal disease. A version in local dialect was used in this field. 
Table 1 Information ascertained systematically from each patient

Age, sex, place of birth, place of residence

Occupation: Farmer, business, landless labourer, professional, etc. Place of work: mostly outdoors, mostly indoors, mixed

Social caste: low, middle, high

Economic status: an index based on income, family size, ownership, etc.

Main source of water: pond, river, unprotected well, well, pump, etc.

Number of years each source used

Cigarette smoking: number per day and years smoked

Tobbaco chewing: years chewed

History of severe life threatening diarrhoeal disease: see Fig. 1

History of heatstroke: number of episodes with year of occurrence

Weight and height: standardised measurements

Screening for diabetes: including urine test

Assessment of visual acuity

Assessment of cataract: central lens opacities

Assessment of the principal cause(s) of visual impairment

Routine diagnostic procedures of the eye unit

exposure to heatstroke was similarly ascertained through use of the local term that referred to a uniformly serious condition, a 'stroke', expected to be a memorable event and accompanied by dehydration. A list of all the interview topics is included in Table 1.

ANALYSIS OF DATA

The data were recorded on predesigned forms which were transferred into a computer database specially designed for management of case control data.

Statistical methods of analysis comprised a rational sequence and mixture of the classical methods ${ }^{3-6}$ and of more recently developed multivariate log-linear modelling techniques. ' Preliminary cross-tabulations were carried out to identify the main factors and their covariates that were strongly associated with the case control status (cataract). The data were then stratified accordingly into multidimensional crosstabulations so that comparisons of cases and controls in respect of exposure to a particular factor could be done within groups that were matched for other key risk factors that might be confounders.

Multivariate log-linear modelling was applied to the stratified data to explore further the interrelationships between exposure factors and cataract. However, the main objectives in log-linear modelling were to confirm the presence or absence of higherorder interactions that might indicate effect modification (that is, heterogeneity of the relative risks in subgroups of the population as defined by the stratification). Summary estimates of the relative risks across the strata were then computed only when justified by the absence of evidence to indicate such heterogeneity.
Associations between cataract and exposure to one or combination of risk factors were quantified by computing the crude and the standardised or summary odds ratios that were so far as possible free of confounding, according to methods proposed by Mantel, Haenszel, and Miettinen..$^{3-5}$ Mantel's extension of the Mantel-Haenszel procedure was used to test the statistical significance of trends in increasing risk of cataract with rising levels of exposure. The computed odds ratios are regarded as estimates of the relative risk and are referred to as such in the paper.

All the various exposure levels considered for each possible risk factor were defined before any data analysis and were not altered at any stage during the data analysis. For example, exposure to dehydrational crises was graded into 4 levels of hypothesised increasing exposure, exactly as for the previous study in Raipur. No other rearrangement or regrading was explored in the analysis.

Information on all the study factors was used to evaluate the relationship between cataract and dehydrational crises. However, only the results that concern the association between cataract and dehydrational crises are reported in this paper. The findings relating to the other risk factors and cataract will be reported in separate publications.

\section{Results}

A total of 1644 consecutive patients aged $30-69$ were examined and interviewed. Of these, 1364 persons were aged 30-59 and comprise the sample for this report.

Examinations identified 434 cases (persons with central lens opacity reducing the vision to less than $6 / 18$ ) and 930 controls. The age and sex distribution of the sample is shown in Table 2. Analysis of the results strongly suggests a marked, consistent, and dose dependent association between: $(a)$ exposure to dehydrational crises (dehydration), as ascertained by history of remembered episodes of severe life threatening diarrhoeal disease and/or heatstroke;

Table 2 Age and sex distribution of 1364 patients in the study

\begin{tabular}{lccccccc}
\hline & $30-34$ & $35-39$ & $40-44$ & $45-49$ & $50-54$ & $55-59$ & Totals \\
\hline Males & 56 & 69 & 90 & 253 & 206 & 207 & 881 \\
Column \% & $75 \cdot 7$ & $67 \cdot 6$ & $53 \cdot 3$ & $62 \cdot 3$ & $61 \cdot 7$ & $74 \cdot 2$ & $64 \cdot 6$ \\
Row \% & $6 \cdot 4$ & $7 \cdot 8$ & $10 \cdot 2$ & $28 \cdot 7$ & $23 \cdot 4$ & $23 \cdot 5$ & $100 \cdot 0$ \\
Females & 18 & 33 & 79 & 153 & 128 & 72 & 483 \\
Column \% & $24 \cdot 3$ & $32 \cdot 4$ & $46 \cdot 7$ & $37 \cdot 7$ & $38 \cdot 3$ & $25 \cdot 8$ & $35 \cdot 4$ \\
Row \% & $3 \cdot 7$ & $6 \cdot 8$ & $16 \cdot 4$ & $31 \cdot 7$ & $26 \cdot 5$ & $14 \cdot 9$ & $100 \cdot 0$ \\
Totals & 74 & 102 & 169 & 406 & 334 & 279 & 1364 \\
Total \% & $5 \cdot 4$ & $7 \cdot 5$ & $12 \cdot 4$ & $29 \cdot 8$ & $24 \cdot 5$ & $20 \cdot 5$ & $100 \cdot 0$ \\
\end{tabular}




\begin{tabular}{|c|c|c|c|c|c|c|c|}
\hline $\begin{array}{l}\text { Age } \\
\text { groups }\end{array}$ & & $\begin{array}{l}\text { Not } \\
\text { exposed }\end{array}$ & Exposed & Totals & $\begin{array}{l}\text { Relative } \\
\text { risk }\end{array}$ & $x^{2}$ & p Value \\
\hline \multirow[t]{2}{*}{$30-34$} & Controls & 59 & 11 & 70 & & & \\
\hline & Cases & 2 & 2 & 4 & $5 \cdot 36$ & 3.03 & 0.082 \\
\hline \multirow[t]{2}{*}{$35-39$} & Controls & 69 & 24 & 93 & & & \\
\hline & Cases & 4 & 5 & 9 & 3.59 & $3 \cdot 53$ & 0.06 \\
\hline \multirow[t]{2}{*}{$40-44$} & Controls & 103 & 29 & 132 & & & \\
\hline & Cases & 13 & 24 & 37 & $6 \cdot 56$ & $24 \cdot 5$ & $<0.001$ \\
\hline \multirow[t]{2}{*}{$45-49$} & Controls & 190 & 95 & 285 & & & \\
\hline & Cases & 60 & 61 & 121 & 2.03 & $10 \cdot 45$ & 0.0012 \\
\hline \multirow[t]{2}{*}{$50-54$} & Controls & 130 & 76 & 206 & & & \\
\hline & Cases & 44 & 84 & 128 & $3 \cdot 27$ & $26 \cdot 04$ & $<0.001$ \\
\hline \multirow[t]{2}{*}{$55-59$} & Controls & 84 & 60 & 144 & & & \\
\hline & Cases & 57 & 78 & 135 & 1.92 & $7 \cdot 21$ & 0.0072 \\
\hline \multirow{3}{*}{$\begin{array}{l}\text { All } \\
\text { ages } \\
\text { Totals }\end{array}$} & Controls & 635 & 295 & 930 & & & \\
\hline & Cases & 180 & 254 & 434 & 3.04 & $88 \cdot 34$ & $<0.001$ \\
\hline & & 815 & 549 & 1364 & & & \\
\hline \multicolumn{8}{|c|}{$\begin{aligned} \text { Summary (unconfounded) relative risk } & =3.02 \\
95 \% \text { confidence limits } & =2.3 \text { and } 4 \\
\text { Summary } \chi^{2}(\text { Mantel/Haenszel }) & =63(\mathrm{p} \text { value }<0.001)\end{aligned}$} \\
\hline
\end{tabular}

Table 3 Association of blinding cataract with any exposure to severe life threatening diarrhoeal disease (one or more remembered episodes). The data are summarised by six age strata only and $(b)$ the risk of visually disabling central lens opacities (cataract).

For exposure to one or more episodes of severe diarrhoeal disease the summary (unconfounded) relative risk estimate was 3.02 with $95 \%$ confidence limits of 2.3 and 3.97 (Table 3 ). This, like the other reported summary estimates, is as far as possible free from confounding by age, sex, and other exposure factors studied. The finding suggests that the actual risk of blinding cataract is on average 3 times higher in those exposed to severe diarrhoeal disease than in those not exposed, in the age range studied. The likelihood is $95 \%$ that the actual relative risk is not less than about 2.3 and not more than about 4 . Loglinear modelling and a classical test of homogeneity indicated that the relative risks were uniform in the various age/sex strata.

There was a significant trend of increasing relative risks with rising level of exposure to severe diarrhoeal disease. The trend was consistent in the various age/ sex strata. In the youngest age group (30-39) the relative risk estimates for exposure to only one episode of severe diarrhoeal disease was about $2 \cdot 3$. For exposure to 2 or more episodes the relative risk was 12. These suggest that the risk of blinding cataract may be increased 2-fold in those with the lower level of exposure and as much as 12-fold in the higher exposure group, all compared with the not exposed. As expected, the trends were not identical in all the strata in the data. However, log-linear modelling indicated that the variations in trend between the strata were small and did not indicate real differences. This lack of convincing evidence for heterogeneity justified computation of overall summary relative risks for each level of exposure to arrive at a summary trend. The summary trends and some of the stratum specific trends are shown in Table 4.
There were consistent and strong 'dose dependent' relationships between risk of cataract and four levels of increasing exposure to dehydrational crises (exposure to diarrhoea and/or heatstroke). The trend was most marked in the youngest age group. However, log-linear modelling again indicated homogeneity across the strata. The summary and some of the age-specific relative risks are shown in Table 5. The trends are displayed in Fig. 2.

Table 4 Trends of increasing risk of blinding cataract with rising levels of exposure to severe life threatening diarrhoeal disease $(0,1$, or $2+$ episodes). The data are summarised by six age strata only. Relative risk $(R R)$ estimates are shown for each 10-year age class

\begin{tabular}{|c|c|c|c|c|c|c|c|}
\hline \multirow[t]{2}{*}{$\begin{array}{l}\text { Age } \\
\text { groups }\end{array}$} & & \multicolumn{4}{|c|}{$\begin{array}{l}\text { Levels of exposure to severe } \\
\text { diarrhoeal disease }\end{array}$} & \multirow[t]{2}{*}{$\begin{array}{l}\text { Trend } \\
\chi^{2}\end{array}$} & \multirow[t]{2}{*}{ p Value } \\
\hline & & 0 & 1 & $2+$ & Totals & & \\
\hline \multirow[t]{2}{*}{$30-34$} & Controls & 59 & 9 & 2 & 70 & & \\
\hline & Cases & 2 & 2 & 0 & 4 & & \\
\hline \multirow[t]{2}{*}{ 35-39 } & Controls & 69 & 19 & 5 & 93 & & \\
\hline & Cases & 4 & 1 & 4 & 9 & & \\
\hline \multicolumn{2}{|c|}{ Relative risks } & 1 & $2 \cdot 3$ & $12 \cdot 2$ & & $10 \cdot 7$ & 0.001 \\
\hline \multirow[t]{2}{*}{$40-44$} & Controls & 103 & 20 & 9 & 132 & & \\
\hline & Cases & 13 & 17 & 7 & 37 & & \\
\hline \multirow[t]{2}{*}{$45-49$} & Controls & 190 & 68 & 27 & 285 & & \\
\hline & Cases & 60 & 36 & 25 & 121 & & \\
\hline \multicolumn{2}{|c|}{ Relative risks } & 1 & $2 \cdot 4$ & $3 \cdot 6$ & & $29 \cdot 2$ & $<0.001$ \\
\hline \multirow[t]{2}{*}{$50-54$} & Controls & 130 & 53 & 23 & 206 & & \\
\hline & Cases & 44 & 42 & 42 & 128 & & \\
\hline \multirow[t]{2}{*}{$55-59$} & Controls & 84 & 46 & 14 & 144 & & \\
\hline & Cases & 57 & 45 & 33 & 135 & & \\
\hline \multicolumn{2}{|c|}{$\begin{array}{l}\text { Relative risks } \\
\text { Total sample }\end{array}$} & 1 & 1.9 & $4 \cdot 3$ & 1364 & $41 \cdot 6$ & $<0 \cdot 001$ \\
\hline \multicolumn{2}{|c|}{$\begin{array}{l}\text { Summary RRs } \\
\text { (Mantel/Haenszel) } \\
\text { Log-linear modellin }\end{array}$} & rata inc & 2 & $4 \cdot 1$ & of the & $78 \cdot 5$ & $<0.001$ \\
\hline
\end{tabular}




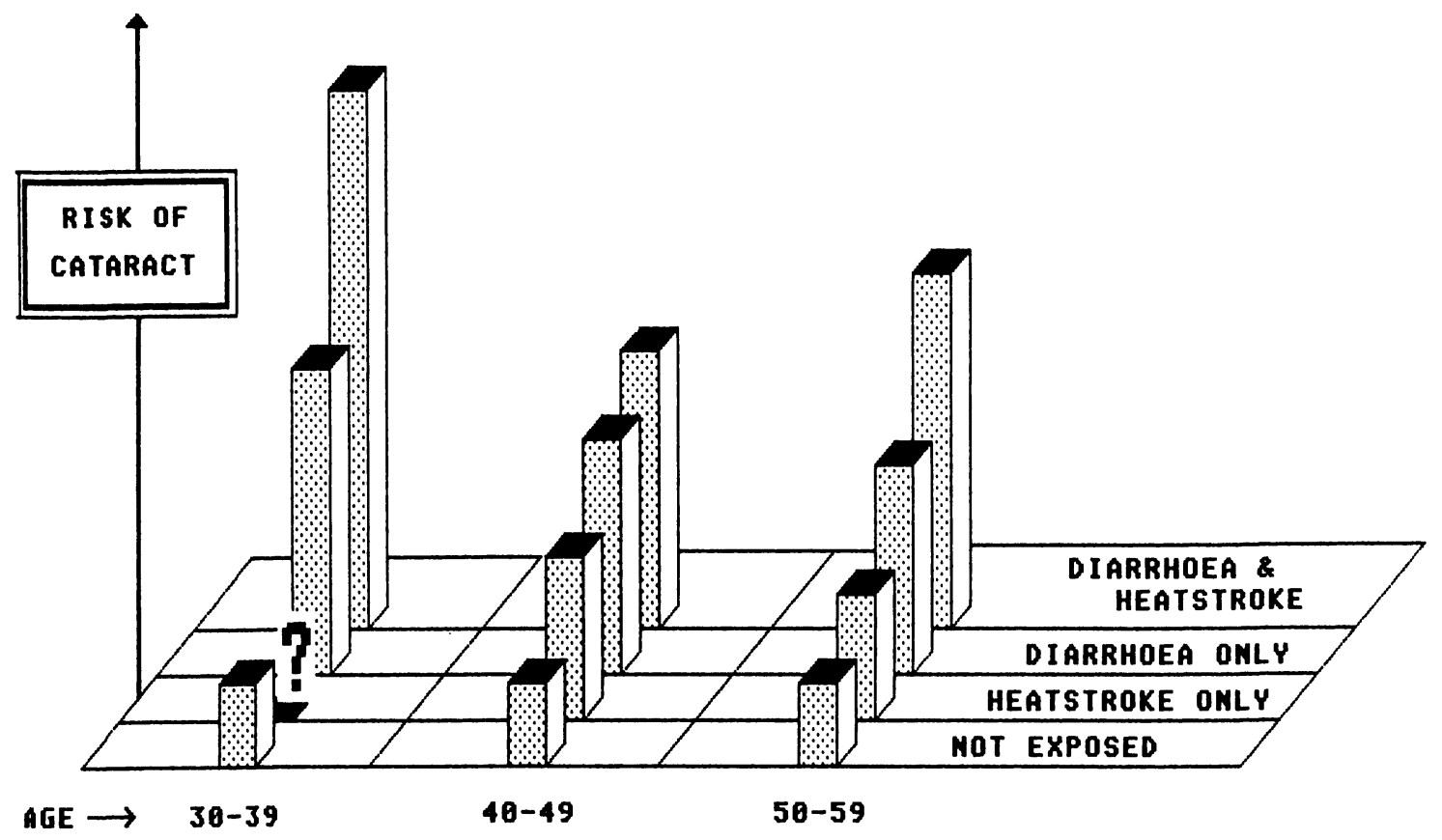

Fig. 2 Trends of increasing risk of blinding cataract with rising levels of exposure to dehydrational crises. The relative risks should not be compared between the age groups, as the baseline risk in each age group is set to 1.

Table 5 Trends of increasing risk of blinding cataract with rising levels of exposure to 'dehydrational crises'. Relative risk $(R R)$ estimates are shown for each 10-year age class

\begin{tabular}{|c|c|c|c|c|c|c|c|}
\hline \multirow{2}{*}{\multicolumn{2}{|c|}{$\begin{array}{l}\text { Age } \\
\text { groups }\end{array}$}} & \multicolumn{5}{|c|}{$\begin{array}{l}\text { Levels of exposure to } \\
\text { dehydrationl crises* }\end{array}$} & \multirow[t]{2}{*}{ p Value } \\
\hline & & 0 & 1 & 2 & 3 & Totals & \\
\hline \multirow[t]{2}{*}{$30-34$} & Controls & 54 & 5 & 10 & 1 & 70 & \\
\hline & Cases & 2 & 0 & 2 & 0 & 4 & \\
\hline \multirow[t]{2}{*}{$35-39$} & Controls & 65 & 4 & 22 & 2 & 93 & \\
\hline & Cases & 4 & 0 & 4 & 1 & 9 & \\
\hline \multicolumn{2}{|c|}{ Relative risks } & 1 & $? ?$ & $3 \cdot 7$ & $6 \cdot 6$ & & 0.008 \\
\hline \multirow[t]{2}{*}{$40-44$} & Controls & 99 & 4 & 28 & 1 & 132 & \\
\hline & Cases & 11 & 2 & 21 & 3 & 37 & \\
\hline \multirow[t]{2}{*}{$45-49$} & Controls & 179 & 11 & 91 & 4 & 285 & \\
\hline & Cases & 55 & 5 & 60 & 1 & 121 & \\
\hline \multicolumn{2}{|c|}{ Relative risks } & 1 & 2 & $2 \cdot 9$ & $3 \cdot 4$ & & $<0.001$ \\
\hline \multirow[t]{2}{*}{$50-54$} & Controls & 121 & 9 & 73 & 3 & 206 & \\
\hline & Cases & 41 & 3 & 82 & 2 & 128 & \\
\hline \multirow[t]{2}{*}{$55-59$} & Controls & 83 & 1 & 59 & 1 & 144 & \\
\hline & Cases & 53 & 4 & 72 & 6 & 135 & \\
\hline \multirow{2}{*}{\multicolumn{2}{|c|}{$\begin{array}{l}\text { Relative risks } \\
\text { Total sample }\end{array}$}} & 1 & $1 \cdot 5$ & $2 \cdot 5$ & $4 \cdot 3$ & & $<0.001$ \\
\hline & & & & & & 1364 & \\
\hline \multicolumn{3}{|c|}{$\begin{array}{l}\text { Summary RRs } \\
\text { (Mantel/Haenszel) } \\
\text { Log-linear modelling in } \\
\text { across the age strata }\end{array}$} & $\begin{array}{l}1.7 \\
\text { ed ho }\end{array}$ & $\begin{array}{l}2 \cdot 7 \\
\text { ogen }\end{array}$ & $\begin{array}{c}4 \\
\text { ty o }\end{array}$ & rend in & $\begin{array}{l}<0 \cdot 001 \\
\text { RRs }\end{array}$ \\
\hline \multicolumn{8}{|c|}{$\begin{aligned} * 0 & =\text { no exposure. } \\
1= & \text { exposed to heatstroke only (one or more episodes). } \\
2= & \text { exposed to severe diarrhoeal disease only (one or more } \\
& \text { episodes). } \\
3= & \text { exposed to both heatstroke and severe diarrhoea. }\end{aligned}$} \\
\hline
\end{tabular}

The overall unconfounded population attributable risk (PAR) for exposure to dehydrational crises was estimated to be about $37 \%$ for each of the age groups $30-39$ and $40-49$, and about $39 \%$ for the oldest age group (Table 6). The summary estimate for the population was $38 \%$. The findings suggest that about $38 \%$ of the visually disabling cataract in the population may be attributed to dehydrational crises.

\section{Discussion}

The findings support the hypothesis of a causal association between repeated episodes of dehydrational crises and blinding cataract. They also suggest that a substantial proportion of visually disabling cataract is avoidable through prevention or control of severe acute dehydration. However, in this as in any

Table 6 Population attributable risks (PARs). Proportion of the blinding cataract that may be attributable to 'dehydrational crises'. The unconfounded estimates of PAR are shown for each 10-year age class and also as a summary measure for the whole data set

\begin{tabular}{lll}
\hline Age groups & $P A R$ & $95 \%$ Confidence limits \\
\hline $30-39$ & $36 \cdot 8 \%$ & \\
$40-49$ & $37 \cdot 3 \%$ & \\
$50-59$ & $38 \cdot 7 \%$ & $26 \%$ and $49 \%$ \\
Summary PAR & $38 \%$ & \\
\hline
\end{tabular}


other case control study, it is possible that the reported relative risks were grossly over- or underestimated because of bias arising from the study and/ or confounding. It is therefore essential to review the main potential sources of bias that might have arisen and to discuss what was done to minimise their undesirable effects.

Possible bias from selection of cases and controls. The study was designed to estimate the risk of visually disabling cataract in patients exposed to dehydrational crises compared with those not exposed. The cases therefore comprised persons with central lens opacities that reduced vision to less than $6 / 18$. The controls 'were the remaining patients attending the clinic. Some of the controls also had lens opacities, but these were not advanced enough or sufficiently central in location to cause serious visual impairment. It would have been inappropriate to exclude such controls from the analysis. Had we done so the estimates of relative risk would be considerably higher, but spuriously so. Furthermore, such exclusions would make it very difficult to interpret the population attributable risks in a useful way.

Possible bias from ascertainment of past exposure. It may be argued that in spite of the great emphasis on the severe life threatening nature of the illness on which the interview focused, many subjects could have been incorrectly classified as exposed (or not exposed) because of poor recollection of the past episodes. This would imply that the method of ascertaining past exposure to dehydrational crises had poor sensitivity and poor specificity in detecting presence or absence of exposure. If this were true, the reported relative risks can only be underestimates. Poor sensitivity and/or poor specificity would tend to mask some component of the relative risks, provided the ability of the interview in detecting past exposure was equally poor (that is, unbiased) in both cases and controls. An important aspect of the repeated quality control checks that were made throughout the study was to ensure that all the subjects regardless of their case control status continued to be interviewed in the same manner by the same interviewer using the standardised method. We are therefore reasonably certain that bias from this potential source was minimal, if any. We are equally certain that our estimates of relative risk are not exaggerated and are best regarded as minima.
Persons were considered exposed only when the episode of exposure preceded the cataract induced visual disability by three months or more. The consistent and marked trend of increasing risk with rising levels of exposure would be difficult to explain in terms other than that of a causal association between cataract and dehydrational crises. The hypothesis of causal association is strengthened by the similarity of the findings to those of the previous study in Raipur (almost identical population attributable risk estimates), particularly in view of the substantial differences in the methods of the two studies and in the environmental and sociocultural characteristics of the two populations studied.

In order to be able to generalise the hypothesis to other populations we strongly recommend that similar investigations should be done (preferably also by other groups of workers) in other locations. However, unless the past exposure to severe diarrhoeal disease is ascertained with great care and due emphasis given to the severity of the episodes, it is unlikely that a relationship could be demonstrated.

Our thanks to Dr Hasmuk for his valuable supervision and for making available the eye unit in his practice, and to Mr Lallit for conducting the interviews and examinations with such great care.

The study was funded by the British Council for the Prevention of Blindness.

\section{References}

1 Minassian DC, Mehra V, Jones BR. Dehydrational crises from severe diarrhoea or heatstroke and risk of cataract. Lancet 1984; i: 751-3.

2 Mehra V, Minassian D. A rapid method of grading cataract in epidemiological studies and eye surveys. Br J Ophthalmol 1988; 72: 801-3.

3 Mantel N, Haenszel W. Statistical aspects of the analysis of data from retrospective studies of disease. $J$ Nat Cancer Inst 1959; 22: $719-48$.

4 Miettinen OS. Standardisation of risk ratios. Am J Epidemiol 1972; 96: 383-8.

5 Miettinen O. Estimability and estimation in case-referent studies. Am J Epidemiol 1975; 103: 226-35.

6 Schlesselman JJ. Case control studies: design, conduct, analysis. Monographs in epidemiology: and statistics. Oxford: Oxford University Press, 1982.

7 Fienberg SE. The analysis of cross-classified categorical data. 2nd ed. Cambridge, Mass: Massachusetts Institute of Technology Press, 1983.

Accepted for publication 7 January 1988. 